Category

Peptide Chemistry

Key words

chemical ligation

peptide bond

acyl transfer

pentadecapeptide
C. - F. LIU, J. P. TAM* (VANDERBILT UNIVERSITY, NASHVILLE, USA)

Chemical Ligation Approach To Form a Peptide Bond between Unprotected Peptide Segments: Concept and Model Study J. Am. Chem. Soc. 1994, 116, 4149-4153.

\section{Chemical Ligation of Unprotected Peptide Segments}

A model study of the chemical ligation strategy:

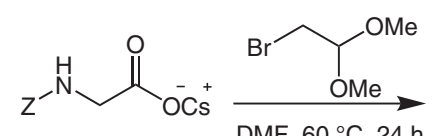<smiles>[Z]NCC(=O)OCC(O[Na])O[Na]</smiles>

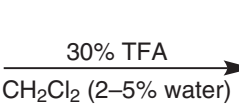

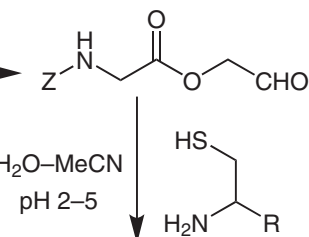<smiles>[Z]NCC(=O)N1C([R])CSC1CO</smiles>

$\mathrm{pH} 4-9$<smiles>[Z]NCC(=O)OCC1NC([R])CS1</smiles>

Synthesis of a model pentadecapeptide by the chemical ligation approach:

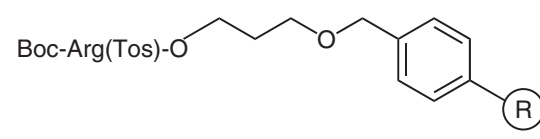

(B) 2. 3 DN synthesis and acetylation

DMSO oxidation
Ac-Cys-Tyr-Thr-Ser-Gly-Cys-Val-Arg-O $\left(\mathrm{CH}_{2}\right)_{3} \mathrm{OH}$

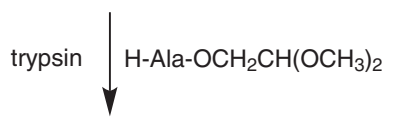

Ac-Cys-Tyr-Thr-Ser-Gly-Cys-Val-Arg-Ala-OCH
Ac-Cys-Tyr-Thr-Ser-

1. TFA

. H-Cys-Thr-Phe-Asp-Leu-Lys- $\mathrm{NH}_{2}$
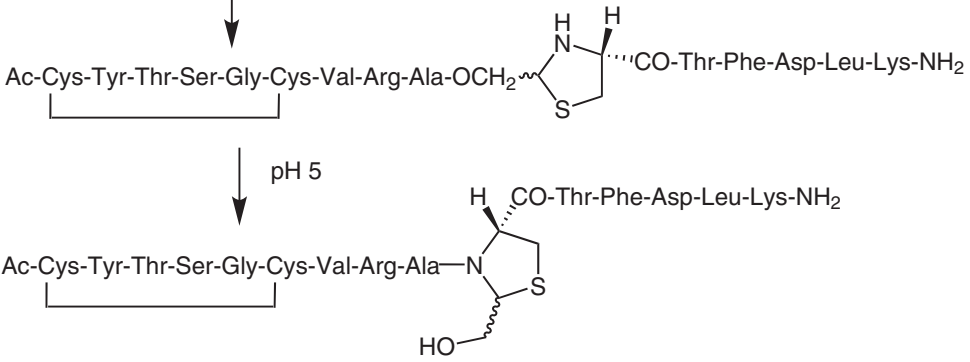

Significance: The authors describe an approach for the chemical ligation of peptide segments by thiazolidine ring formation. The method does not require protecting groups or the activation of the $\mathrm{C}^{\alpha}$-carboxyl group in the conventional sense. The main feature of the approach is that it overcomes the entropy barrier to intermolecular reaction between two large molecules. Furthermore, this method was successfully used in the synthesis of a pentadecapeptide.
Comment: This chemical ligation approach of unprotected segments proceeds through three steps: (1) introduction of an aldehyde group at a C-terminal site, (2) ring formation, and (3) O-to-N acyl transfer. These steps eliminate the need for protecting groups and permit the ligation to proceed in aqueous solution. 